Primljen / Received: 26.3.2012 Ispravljen / Corrected: 17.7.2012

Prihvaćen / Accepted: 20.7.2012

Dostupno online / Available online: 30.7.2012.

\section{Conditions for simultaneous formation of multigroup freight trains}

Authors:

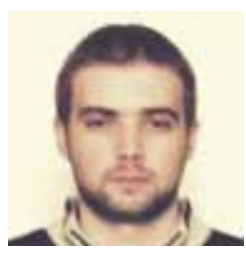

Ivan Belošević, dipl.ing.prom

Sveučilište u Beogradu

Prometni fakultet

i.belosevic@sf.bg.ac.rs

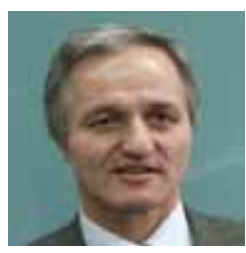

Prof.dr.sc. Miloš Ivić, dipl.ing. prom.

Sveučilište u Beogradu

Prometni fakultet

m.ivic@sf.bg.ac.rs

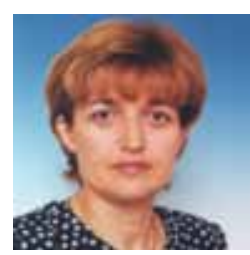

Mr.sc. Milana Kosijer, dipl.ing.građ.

Sveučilište u Beogradu

Prometni fakultet

m.kosijer@sf.bg.ac.rs
Ivan Belošević, Miloš Ivić, Milana Kosijer

\section{Conditions for simultaneous formation of multigroup freight trains}

The multigroup freight train formation is regarded as a challenging problem in railway transport. Multigroup trains are composed of a number of wagon groups that have to be arranged according to the order of intermediate stations. The analysis of technical and technological conditions that significantly influence the effects of simultaneous train formation methods is presented. The effects of various methods of significance for track capacity planning and train station service level analysis are considered. The research presented in the paper is expected to contribute to the process of planning measures to be taken prior to construction of train stations.

Key words:

marshalling yards, freight train formation, simultaneous methods, railway infrastructure, simulation model

Prethodno priopćenje

Ivan Belošević, Miloš Ivić, Milana Kosijer

Uvjeti za simultano formiranje višegrupnih teretnih vlakova

Formiranje višegrupnih teretnih vlakova predstavlja jedan od kompleksnijih problema željezničkog prometa. Višegrupni vlakovi se sastavljaju od većeg broja grupa vagona koje treba sortirati u kompoziciju prema redoslijedu međukolodvora na pruzi. U radu je prikazana analiza tehničko-tehnoloških uvjeta koji bitno utječu na efekte primjene metoda simultanog formiranja vlakova. Razmatrani su efekti pojedinih metoda značajni za planiranje kolosiječnih kapaciteta i kvalitetu rada kolodvora. Istraživanje u ovom radu doprinosi procesu planiranja u cilju poduzimanja odgovarajućih mjera prije izgradnje kolodvora.

Ključne riječi:

ranžirni kolodvori, formiranje teretnih vlakova, simultane metode, željeznička infrastruktura, simulacijski model

Übersichtsarbeit

Ivan Belošević, Miloš Ivić, Milana Kosijer

\section{Bedingungen für eine simultane Formierung von Mehrgruppen-Lastzügen}

Die Formierung von Mehrgruppen-Lastzügen stellt eines der komplexeren Probleme des Eisenbahnverkehrs dar. Mehrgruppenzüge setzen sich aus einer größeren Waggongruppe zusammen, die man in eine Komposition nach der Reihenfolge der Zwischenstationen sortieren muss. In der Arbeit ist die Analyse der technisch-technologischen Bedingungen dargestellt, die bedeutend auf die Effekte der Anwendung der Methode der simultanen Zugformierung Einfluss nehmen. Es wurden die Effekte einzelner Methoden in Erwägung gezogen, die für die Planung von Gleiskapazitäten und die Arbeitsqualität des Bahnhofs von Bedeutung sind. Die Forschung in dieser Arbeit trägt dem Planungsprozess zum Zwecke der Umsetzung entsprechender Maßnahmen vor dem Ausbau des Bahnhofs bei.

Schlüsselwörter:

Rangierbahnhöfe, Formierung von Lastzügen, simultane Methoden, Eisenbahninfrastruktur, Simulationsmodell 


\section{Introduction}

In the course of their historic development, railways have transformed from isolated railway lines connecting local industrial centres into a complex system, with the general tendency toward achieving a uniform continental railway network. Through this rail network forming process, railway stations have emerged as key components for ensuring efficient functioning of railway transport. At the same time, these stations have been faced with a whole array of problems relating to infrastructure capacity dimensioning and work technology planning. These problems are in fact basic optimisation problems affecting railway transport in general.

The issue of marshalling or shunting, as one of basic characteristics of cargo transport by railway, is specific to specialized marshalling or classification yards. The formation of multigroup trains is considered a highly complex marshalling issue. Multigroup trains are composed of a number of railway vehicle groups that have to be classified according to the order of intermediate stations. The marshalling process itself is specific for this type of transport, as it enables adjustment of railway service to fit the needs of the economy. Unfortunately, marshalling is not devoid of disadvantages: it requires additional track capacities and increases the downtime of vehicles, which finally results in an increase of transport costs and in lower quality of service. It can generally be acknowledged that marshalling yard capacities are not used to their full potential. This statement is confirmed by analysis of operation of such yards [11], which shows that the number of yards where capacities are underused is much greater when compared to the number of those characterized by overuse of capacities. This means that a lack of harmony exists between track capacities, marshalling technology used, and the scope of operation for which such yards were designed.

Methods for forming multigroup trains were first formulated and classified in the mid twentieth century at professional conferences and in journals dealing with practical issues of railway transport $[1,16]$. This initial activity was followed by publication of first scientific papers relating to marshalling yards, in which the structure and processing capacities of such yards were defined $[2,14,15]$. After these first scientific formulations and considerations relating to the issue of marshalling, the scientific activity continued with other papers $[4,5]$ in which multigroup train forming methods were formulated mathematically. Recent research $[6,7]$ shows that that the multigroup train forming problem belongs to the complexity class NP (nondeterministic in polynomial time). Development of simulation techniques has enabled analysis of performance of methods applied in real-time conditions, by varying different environment parameters. Simulation models for multigroup train forming methods are described in papers $[9,13]$. The performance or efficiency of consecutive forming methods is analyzed in paper [9], and the possibility of using various methods in several marshalling yards in the Slovak Republic is considered in paper [13].
Technical-technological conditions that significantly influence the effects of the use of simultaneous multigroup train forming methods are analyzed in this paper. Research conducted so far has not placed sufficient emphasis on operating conditions and on marshalling yard design requirements, which in some cases puts into question possibilities for realization of theoretical formation plans. Simulation models based on real technicaltechnological conditions are developed in this paper. These models are capable of answering the question about track capacities needed for the use of mentioned methods, and about performance that can be expected in the train forming process, and this before the yard is actually built and used.

After introduction, the paper continues with presentation of the multigroup train forming problem. A brief overview of existing simulation methods is given in the scope of this presentation. Technical and technological requirements for their use are analyzed in the third section. At that, a special attention is paid to the number, length, and interconnection capability of tracks, and to technological cycle of operations to be completed during train formation. Simulation model that is used for further performance analysis of simultaneous methods is presented in section four. Final considerations and proposals for further research are given in the final section.

\section{Problem description}

Multigroup trains are formed of two or more groups of vehicles that are marshalled separately, each one by itself, depending on their destinations. Formation of multigroup trains shortens the time needed for collection, and enables concentration of manoeuvring operations to a smaller number of marshalling yards. This concentration of manoeuvring operations leads to greater use of track capacities, manoeuvring facilities and personnel, while also enabling rationalization of capacities and operating technology at intermediate and final stations where manoeuvring is reduced to separation of vehicle groups that have already been formed.

According to traditional concept of cargo transport by railway, multigroup trains are primarily represented in the local transport segment, through the shunt trains category. The objective of shunt trains is to deliver and collect vehicles by intermediate stations, and to transport them further to the next marshalling yard. At the starting station, the shunt train is formed by placing cars for each intermediate station into a separate group, and by distributing groups according to the order of intermediate stations. According to the new concept of transport, the railway transport is changed in order to establish a unified transport system. By establishment of the new concept, multigroup trains have been gaining more significance in the segment of long-distance transport as well. Long-distance multigroup trains play a role in connecting a number of terminals in a region so as to ensure that small flows of cargo are connected at a part of their transport route, thus forming integrated block trains.

Multigroup trains also play a significant role in the industrial railway transport, which is a significant link in the transport chain between the industry and public transport. Industrial railways are 
characterized by a highly developed track network, with a number of manipulation points, and this network is in many instances subdivided into a number of sections providing services to industrial marshalling yards. The role of industrial marshalling yards lies in formation of industrial trains in which vehicles are grouped according to the order of manipulation points, to enable faster and simpler delivery.

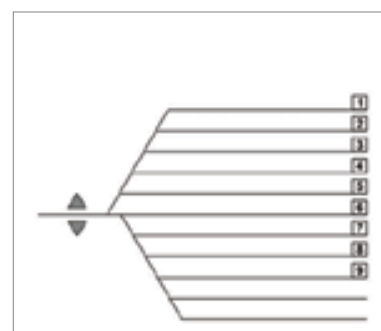

$$
\text { 1. Faza - nakupljenje vagona }
$$
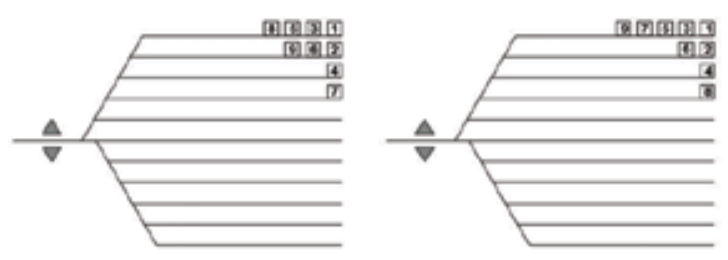

2. Faza - sortiranje vagona

1. Korak sortiranja
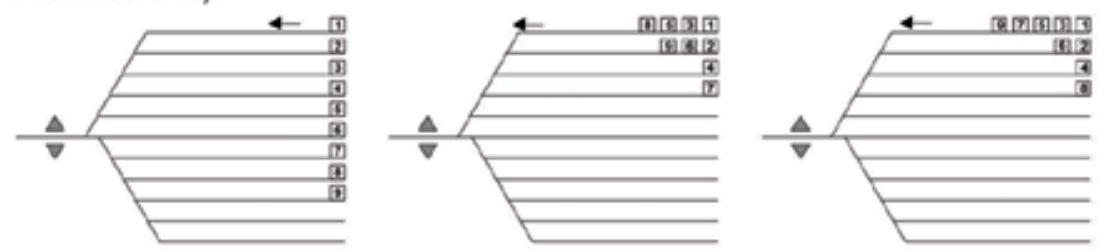

2. Korak sortiranja
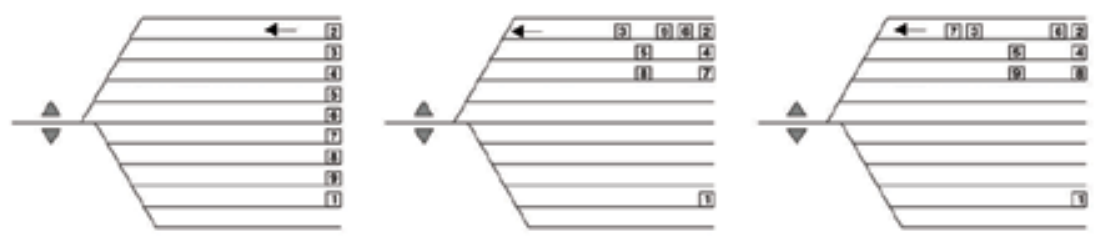

3. Korak sortiranja
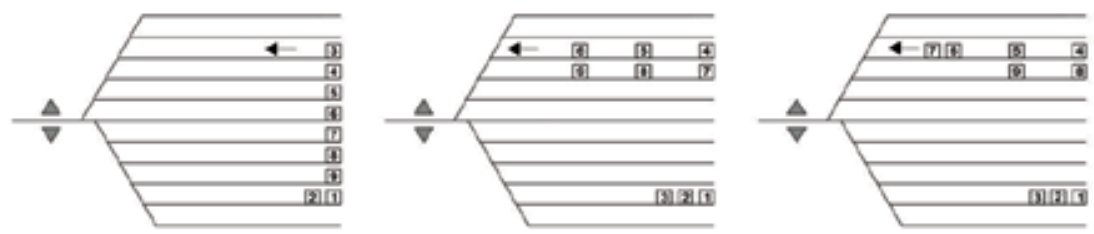

4. Korak sortiranja
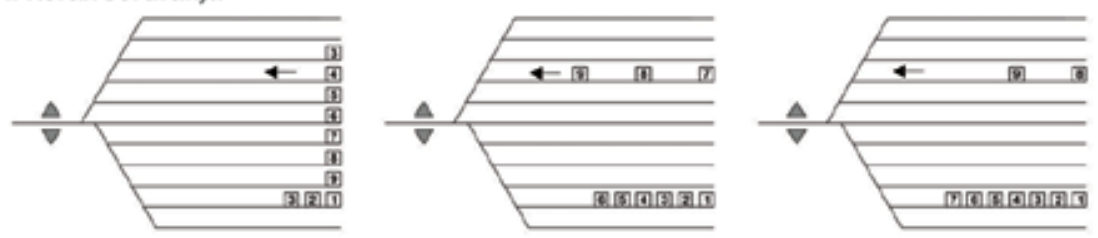

Kraj procesa formiranja

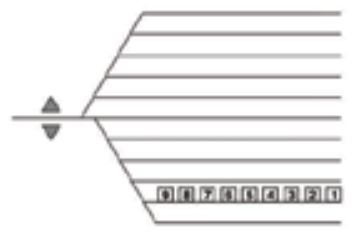

A) Elementarna metoda

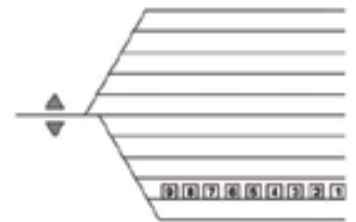

B) Trokutna metoda

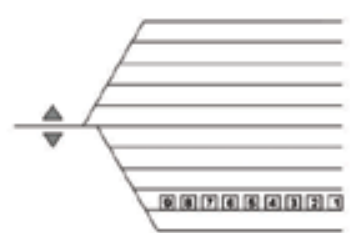

C) Geometrijska metoda

Figure 1. Current simultaneous methods for multigroup train forming

\subsection{Methods for simultaneous formation of multigroup trains}

Methods for simultaneous formation of multigroup trains are generally divided into methods for consecutive formation of trains, and methods for simultaneous formation of trains. According to consecutive formation methods, which are more frequently used in railways, the next train can not be formed before formation of the previous train is completed. The distinguishing feature of simultaneous methods primarily lies in the fact that vehicles are collected according to the order of appropriate intermediate stations, i.e. according to vehicle groups belonging to intermediate stations of the same number for different trains, rather than according to trains. This brings about the difference in the use of track capacities, and hence in the realization of the overall forming process. Simultaneous methods can greatly improve station operating parameters, as they enable simultaneous formation of several trains, which in turn enables their timely dispatch from marshalling yards and delivery of vehicles to their destinations. Simultaneous methods formulated so far, i.e. elementary, triangular and geometric ones [5], are presented in this paper (Figure 1.).

Simultaneous methods were used for the first time in French railways in 1917, when numerous trains had to be formed to ensure supply of various cargo to French army at the front toward Germany, during World War One [1].

\subsubsection{Elementary simultaneous method}

The elementary simultaneous method (Figure 1-A) consists of two phases. In the first phase, vehicles are collected according to intermediate stations. Vehicle collection is performed in such a way that vehicles for all first, subsequent and all other intermediate stations are brought to tracks previously determined for each intermediate station, despite the fact that vehicles belong to different trains. The theoretical minimum number of tracks for collection $\left(n_{k}\right)$ is equal to 
the maximum number of intermediate stations $\left(g_{\max }\right)(1)$. The rule for collection of groups of vehicles $g_{j}\left(j=1, \ldots, g_{\max }\right)$ by track is given in the expression (2), where $g_{k}$ is the number of intermediate stations for trains from which vehicles are gathered at the track $\mathrm{k}$ :

$n_{k}=g_{\text {max }}$

$g_{k}=g_{j}, k=j=1, \ldots, g_{\max }$

After completion of collection phase, the second phase (formation phase) is implemented. In this phase, vehicles are moved from collection tracks, and are grouped according to the corresponding trains. The elementary simultaneous method enables formation of a great number of multigroup trains with a minimum scope of manoeuvring work (number of moves is equal for all groups and amounts to precisely one move per vehicle $(h=1)$, and the number of vehicles moved, i.e. of vehicles which were used in the multigroup train forming process, corresponds to the total number of vehicles in all trains.

\subsubsection{Triangular method}

Theoretical bases for triangular method are presented in full detail in paper [4] and so only basic triangular sorting indicators are given in this text. In principle, this method also consists of two phases (Figure 1-B). Vehicles are gathered together in the first phase, and are sorted in the second phase. In the second phase, they are partly sorted (at vehicle collection tracks) according to intermediate stations, and partly (at train forming tracks) according to trains they belong to, and according to the order of intermediate stations. The connection between the maximum number of intermediate stations in a train $\left(g_{\max }\right)$ and the required number of vehicle collection tracks $\left(n_{k}\right)$ is shown in the expression (3):

$n_{k}= \begin{cases}\sqrt{2 g_{\max }}-\frac{1}{2}, & \sqrt{2 g_{\max }}-\frac{1}{2} \in N \\ {\left[\sqrt{2 g_{\max }}-\frac{1}{2}\right],} & \sqrt{2 g_{\max }}-\frac{1}{2} \notin N\end{cases}$

The rule for collecting vehicle groups $g_{j}\left(j=1, \ldots, g_{\max }\right)$ at intermediate stations and tracks $\mathrm{k}$ is given in the expression (4), where vehicles for intermediate stations are collected at track $k$ at point $i[4]$ :

$g_{k, i}=\frac{k(k-1)}{2}+i k+1+\frac{(i-1)(i-2)}{2}, \quad k=1, \ldots, n_{k}, \quad i=1,2,3,4, \ldots$

Unlike the elementary method, in case of triangular forming, vehicles for more than one intermediate station are collected at a single track. This calls for a more complex classification plan, and hence a greater scope of manoeuvring operations, such as the number of pullout operations per vehicle or the number of vehicles moved. The number of pullout operations is two for all vehicles belonging to the same intermediate station, except for vehicles (4a), which represent the so called "frontal groups" at tracks $k$, and are pulled out once $(h=1)$. In practice, this means that these vehicles pass through the forming process in the same way as in the elementary simultaneous method. As to the number of vehicles moved, with which the multigroup train forming process was accomplished, it is greater than the total number of vehicles in all trains, as up to two pullout operations are made with some trains.

$g_{k, 1}=\frac{k(k-1)}{2}+1$

\subsubsection{Geometrical method}

The geometrical classification (Figure 1-C) constitutes a further advance in the development of simultaneous methods. In fact, an additional reduction in the number of tracks needed for train forming operations has been achieved by using this method. A detailed description of geometrical method is given in papers $[5,10]$. The connection between the maximum number of intermediate stations in a train $\left(g_{\max }\right)$ and the required number of shunting tracks $\left(n_{k}\right)$, where vehicles are collected and sorted according to groups belonging to the same intermediate station, is given in the relation (5), while the general principle for collecting vehicles at tracks is given in the relation (6).

$$
\begin{aligned}
& n_{k}= \begin{cases}\log _{2}\left(g_{\max }+1\right), & \log _{2}\left(g_{\max }+1\right) \in N \\
\left\lceil\log _{2}\left(g_{\max }+1\right)\right\rceil, & \log _{2}\left(g_{\text {max }}+1\right) \notin N\end{cases} \\
& g_{k, i}=2^{k-1}+2^{k}(i-1), \quad k=1, \ldots, n_{k}, i=1,2,3,4, \ldots
\end{aligned}
$$

The reduction in the number of tracks according to this method leads however to an increase in the scope of manoeuvring operations, with respect to both the pullout operations and the number of vehicles moved. The number of vehicle pullout operations is dependent on the number assigned to the intermediate station the vehicles belong to, and may amount to no more than $h=\left[\log _{2} g\right]$. Just like in triangular method, the "frontal groups" have the lowest number of pullout operations, as vehicles are pulled out only once $(h=1)$. Unlike the triangular method, the number of pullout operations for other groups is not limited to a particular value, but rather varies with the change of intermediate stations for a train. In case of geometrical classification, the frontal track group $k$ is the group $g_{k, 1}=2^{k-1}$. A comparative view of the number of required tracks, as related to the number of intermediate stations, is given in Figure 2 for simultaneous methods under study. 


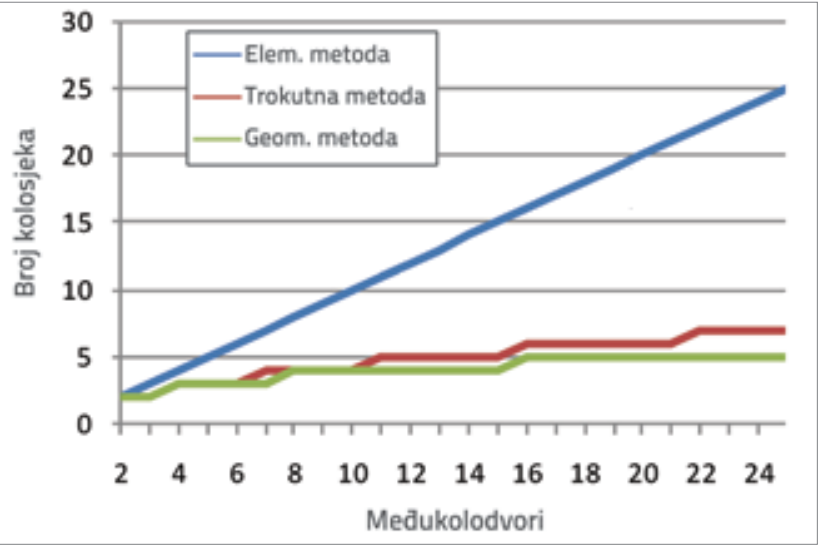

Figure 2 Number of tracks for simultaneous methods

\section{Technical-technological conditions for using simul- taneous methods in multigroup train forming}

The first phase of simultaneous formation of multigroup trains (the so called phase of vehicle collection according to intermediate stations), and the first part of the second phase (the so called phase of vehicle classification according to intermediate stations), take place at tracks of the marshalling or marshallingdeparture park, while the second part of the second phase (the so called vehicle sorting phase according to trains and intermediate stations) can be operated for all methods on tracks of the marshalling or marshalling-departure park, and for elementary method even on tracks of the departure park. In theory, both the pullout track and hump could be used for processing plant but, due to the character of operations (simultaneous formation of a number of trains), the hump is dominantly used in practice. A hump over which the primary shunting operations for train separation are conducted (Figure 3), or a separate auxiliary hump at the exit of the marshalling yard, can both be used for formation of multigroup trains. The auxiliary hump can be a lower height facility, which simplifies its erection.
As already mentioned, simultaneous methods require two groups of shunting tracks (group for collecting and sorting vehicles according to intermediate stations, and group for sorting vehicles according to trains and intermediate stations). From the standpoint of planning and design of railway stations, it is significant to analyze technical and technological conditions for practical implementation of forming methods. Technical conditions include the required number and length of tracks, the way in which the connection between the collection track and hump is realized, and maximum size of composition during pullout. Technological conditions are technological operations that have to be conducted in order to form multigroup trains. One of basic technological indicators is the duration of technological cycle.

\subsection{Number of tracks}

The minimum number of tracks for the collection and sorting according to intermediate stations $\left(n_{\mathrm{k}}\right)$ is defined in the previous section (during definition of theoretical premises), and the number of tracks for sorting vehicles according to trains and intermediate stations is equal to the number of trains that have to be formed at the same time $(m)$. Consequently, the total number of tracks ( $n$ ) that is needed in marshalling yard for vehicle collection and multigroup train forming, is given in the expression (7). Here it should be noted that at least one track on which vehicles were collected (track from which the collected vehicles are pulled out first) can be used for forming one multigroup train, and that the total number of tracks will then be reduced by one, and so the expression (7) will gain a new form (8). If the number of vehicle groups by trains that are formed is not uniform, then the total number of tracks can be further reduced using the same principle:

$$
\begin{aligned}
& n=n_{k}+m \\
& n=n_{k}+m-1
\end{aligned}
$$

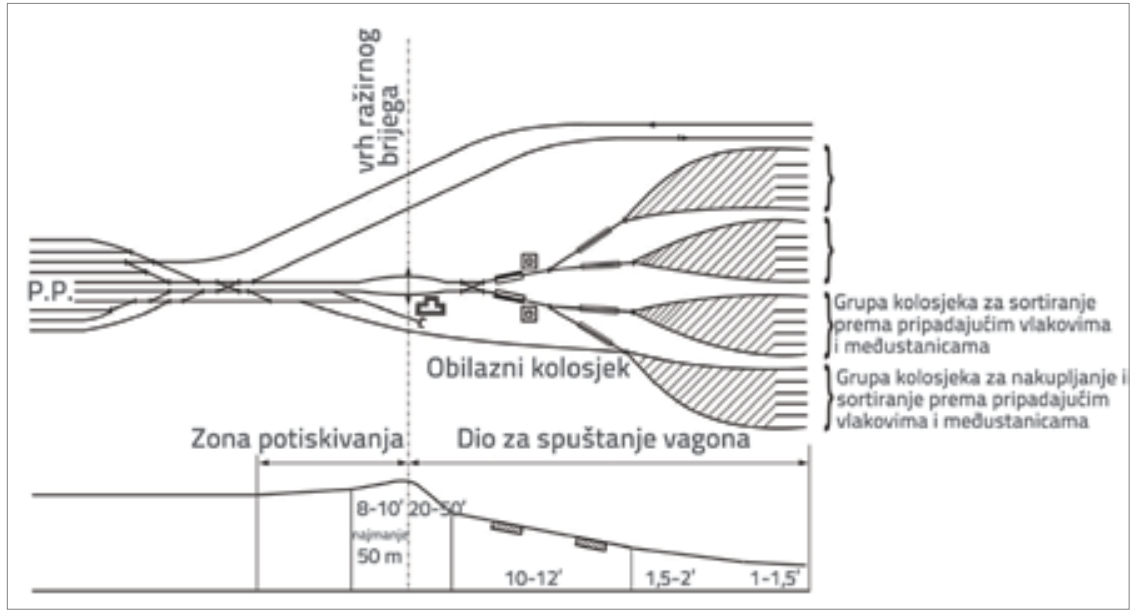

Figure 3. Schematic diagram of a marshalling yard

\subsection{Track lengths}

Lengths of tracks for vehicle collection and sorting according to intermediate stations are directly dependent on the flow of multigroup train wagons, and on the simultaneous forming method applied. This results in an uneven length of tracks and, in some cases, in the requirement that some tracks must be very long. In order to enable interconnection of tracks, their lengths must be uniform and adjusted to operating conditions, which means that the length of relatively short tracks must be increased, while excessively 


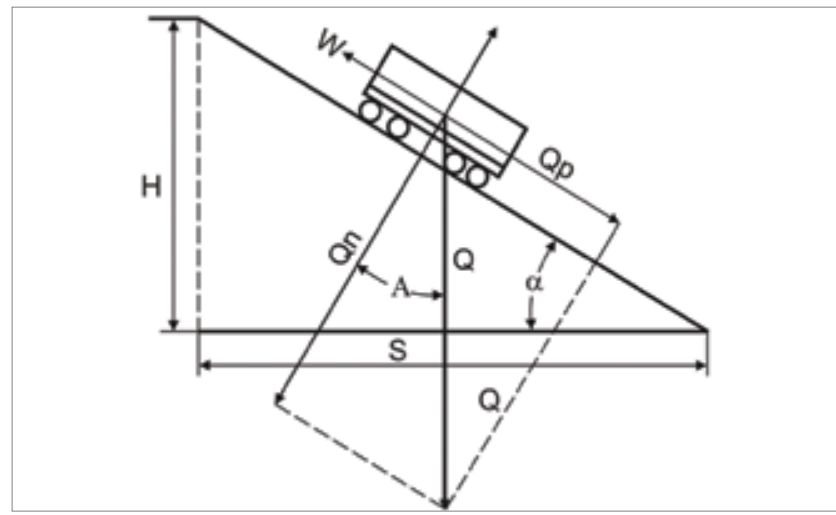

Figure 4. Mathematical model for vehicle movement down the hump

long tracks will have to be divided into two or more tracks, in accordance with operating conditions. Lengths of tracks for vehicle sorting according to trains and intermediate stations must enable accommodation of already formed train compositions that are awaiting departure. The length of multigroup trains does not differ considerably from the length of single-group trains, which is why these lengths can easily fit into track lengths planned for a marshalling yard.

When using the hump, railway vehicles are moving by gravity in the course of shunting operations, and this movement by gravity has to enable arrival of vehicles onto shunting tracks. In order to avoid delay during forming operations due to the need to compress the vehicles, it is advisable to enable vehicle displacement until the end of shunting tracks. This practically means that lengths of tracks for collection of vehicles must be brought into harmony with hump height. In fact, the hump height greatly influences structural and functional properties of marshalling yards, and hence the cost of the construction, maintenance and shunting operations.

The mathematical model for vehicle movement down the hump can be defined as compulsory movement of a material point along steep plane under the influence of gravity (Figure 4). Based on this formulation of vehicle movement model, the maximum length of shunting track for collection of vehicles can be obtained using the energy height method [12]. The energy height method describes the change in total vehicle energy in the course of movement (Figure 5). The full energy height corresponds to the energy the vehicle has at the top of the hump. In the course of shunting operations, the vehicle energy is reduced as total resistances are being overcome (9). The total resistance is the sum of all resistances acting on vehicles during movement (basic vehicle resistance $W_{O}$ resistance from the middle $W_{S^{\prime}}$ resistance from the pullout $W_{s k r}$ resistance from the curve $W_{k}$ :

$H_{g}+h_{v_{o}}-\sum h_{w}-h_{v_{k}}=0$

where:

$H_{g}$ - hump height

$h_{v o}$ - energy height corresponding to initial speed

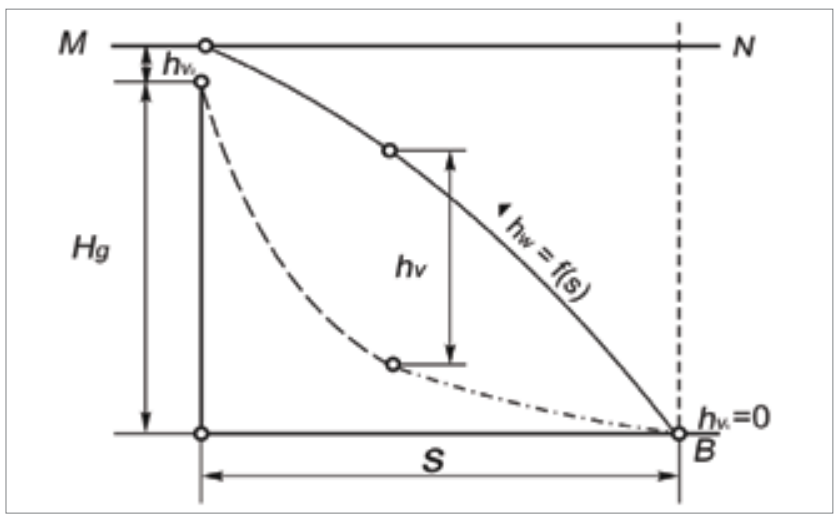

Figure 5. Energy height of vehicle when moving down the hump

$h_{v k} \quad$ - energy height corresponding to speed at the end of track $\sum h_{\text {wo }}$ - energy height loss due to resistance; it can be expressed as (10):

$\sum h_{w}=h_{w_{o}}+h_{w_{s r}}+h_{w_{s k r}}+h_{w_{k r}}$

Assuming that the value of basic specific resistance and specific resistance in the middle is constant on the movement path $S$ consisting of a part of track connections $S_{s /}$ and an another part that can be used for accommodation of vehicle $\mathrm{S}_{\mathrm{k}^{\prime}}$ we obtain the following expression for energy height (11):

$H_{g}+h_{v_{o}}-10^{-3}\left[S_{s l}\left(w_{o}+w_{s r}\right)+S_{k}\left(w_{o}+w_{s r}\right)+h_{w_{s t r}}+h_{w_{k r}}\right]-h_{v_{k}}=0$

This equation is used to obtain the shunting track length dependant on the hump height (12).

$S_{k}=\frac{H_{g}+h_{v_{o}}-h_{v_{k}}-10^{-3}\left[S_{s l}\left(w_{o}+w_{s r}\right)+h_{w_{s t r}}+h_{w_{k r}}\right]}{\left(w_{o}+w_{s r}\right)}$

\subsection{Connection of shunting tracks with the hump}

Shunting tracks can be connected with the hump by planning one or two bypass tracks that should be parallel to the hump. Each bypass track is directly linked with one shunting track bundle. One bundle can be made of $6,8,10$ or 12 tracks. If it becomes necessary to collect vehicles on tracks that are not directly linked to the bypass track, then they are pulled out via the shunting park exit and by back movement using one of tracks from the directly linked bundle. In this case, the operating technology is more complex, and the forming time is therefore longer.

\subsection{Maximum mass of the composition}

Manoeuvring locomotives are a resource whose technicaloperating characteristics highly influence usability of methods discussed in this paper. This primarily concerns limitations regarding maximum mass of composition during pullout, which is dependent on pullout capabilities of locomotives. As the pullout time is linearly dependent on the number of 
vehicles that are being pulled out, it can be concluded that the most comprehensive strategy would involve a combined pullout of all vehicles from the track. For that reason, the total mass of vehicles that are collected on one track must not exceed the maximum allowable mass of the composition, calculated based on traction force of the locomotive (13):

$Q_{s a s}=\frac{F_{v}}{\left(\sum w+i_{s v}\right)}-Q_{i}$

where:

$Q_{\text {sas }}$ - mass of the composition [t]

$Q_{1}$ - mass of the locomotive [t]

$F_{v} \quad$-traction force of the shunter [N]

$\Sigma W$ - sum of specific resistances acting on composition during pullout [N/kN],

$i_{s v}$ - derived inclination at the pullout section [\%]

\subsection{Technological cycle}

The technological cycle is the time during which the hump is occupied with all manoeuvring operations needed to sort the composition that is pulled out of the vehicle collection track. The time needed to complete one manoeuvring operation can be determined via work standardisation, traction analyses, or chronometric surveys [3]. In case of standardisation of work time, the initial assumption is that the manoeuvring time can be expressed by the following linear dependence (14):

$t_{\text {man }}=a+b x_{\text {sas }}$

where:

$t_{\text {man }}$ - duration of technological operation [min]

$x_{\text {sas }}-$ number of vehicles in the composition

$a, b \quad$ - standard parameters of linear dependence.

The total duration of all manoeuvring and technological operations can be standardised by unification, and so the technological cycle can be calculated as follows (15):

$T_{c}=A+B x_{\text {sas }}$

where:

$T_{c} \quad$ - technological cycle [min]

A, $B$-standardised parameters, including the locomotive idling time per composition, compression and connection of composition, pulling out the composition from the shunting track, composition collection and sorting.

\section{Simulation models for multigroup train forming methods}

Simulation models developed for the purposes of this paper were designed in such a way to enable modelling of the technological work processes corresponding to real-life conditions, based on the use of simultaneous methods. The basic objective of the simulation is to obtain, via simulation models, realistic process forming indicators, based on technical-technological conditions which are regarded as limitations from the standpoint of use and design of marshalling facilities.

The following input parameters were adopted for the development of such simulation models:

- Maximum length of a vehicle collection track, limited by hump design requirements, is equal to collection length for fifty average-sized vehicles. The hump height value, needed in the analysis of maximum track length, was adopted based on the analysis of marshalling yards operated by Serbian Railways and marshalling yards used in surrounding regions. Basic vehicle resistances were adopted taking into account the rolling stock structure in railway networks under study, while other required parameters (such as the resistance in the middle) were adopted in keeping with guidelines for the design of marshalling yards, published by German Federal Railways.

- From the standpoint of shunter traction capacity, the maximum number of vehicles in a composition amounts to 34 average-sized loaded vehicles. Traction characteristics of shunters used in the above mentioned marshalling stations were adopted for purposes of this paper.

- Duration of operations comprised in the technological cycle were standardised based on statistical sample obtained by surveys made within the network operated by Serbian Railways [8]. These surveys have revealed that an exponential distribution, with parameters as shown in Table 1, can be assumed during implementation of technological operations. Duration of manoeuvring operations was determined based on traction calculations, and it was established that the duration of technological cycle can be represented with the following functional dependence: $T_{c}=19,1+0,7 x_{\text {sas }}$.

Table 1 Exponential distribution of technological operations

\begin{tabular}{|c|c|}
\hline Technological operation & Matemathic expectation $M(X)$ \\
\hline Connection of vehicles & 0.70 \\
\hline Separation of vehicles & 0.33 \\
\hline Sorting of vehicles & 0.23 \\
\hline
\end{tabular}

The sensitivity of methods to change, both with regard to change in wagon flow to be formed at the same time, and with regard to number of intermediate stations in multigroup trains, was also considered in the scope of mathematical simulations. Arrival conditions for wagon flows, ranging from 50 to 250 vehicles per forming cycle, were analyzed. The 
influence of the number of intermediate stations in formed trains was tested by varying the number of intermediate stations (from 5 to 20). At that, a uniform distribution of vehicles per intermediate stations was assumed. Such a wide range of intermediate stations for train forming was assumed so that it can also be applicable to pick-up train forming conditions (the number of intermediate stations for which pick-up trains are formed does not usually exceed 10), but also to industrial train forming conditions (the number of manipulation points can amount to 20 or more). Thirty simulations were made for each case of operating conditions in order to obtain indicators with high level of relevance.

Simultaneous methods for multigroup train forming do not depend on the number of trains to be formed, and so it is not necessary to analyze influence of the change in the number of trains formed. As already known from various theoretical analyses, the number of trains to be formed influences only the required number of tracks in the second group of tracks (tracks for distribution of vehicles according to trains and intermediate stations).

\subsection{Analysis of results}

Simulation results significant for track capacity planning are presented in the analysis of results. Indicators relating to quality of service in stations, i.e. those aimed at checking functionality of the system using simultaneous multigroup train forming methods, are also analyzed. The basic reason for such selection of indicators is the need to evaluate newlydesigned marshalling yard solutions so that appropriate measures can be taken before stations/yards are actually built and put to service. Theoretical indicators that do not take into account practical and design limitations were first considered in the analysis of results. This was followed by analysis of indicators occurring in real-life conditions, which include the above limitations. Simulations made on theoretical models and models containing real-life operating conditions, enable mutual comparison and analysis of these models.

\subsubsection{Use of track capacities}

Indicators significant for planning track capacities primarily include the number and the length of tracks that are needed in implementation of the forming process. In addition to these two basic indicators, it is also necessary to thoroughly analyze the uniformity of track lengths. The uniformity was measured by defining the mean deviation from maximum value. This dissipation indicator points to deviation of track lengths with respect to the longest track.

The theoretical number of tracks needed for collection and sorting according to the number of intermediate stations, is obtained based on the formulation of dependencies (1), (3), (5) that are described in the scope of theoretical explanation of methods (Section 2.1). Individual theoretical track lengths are

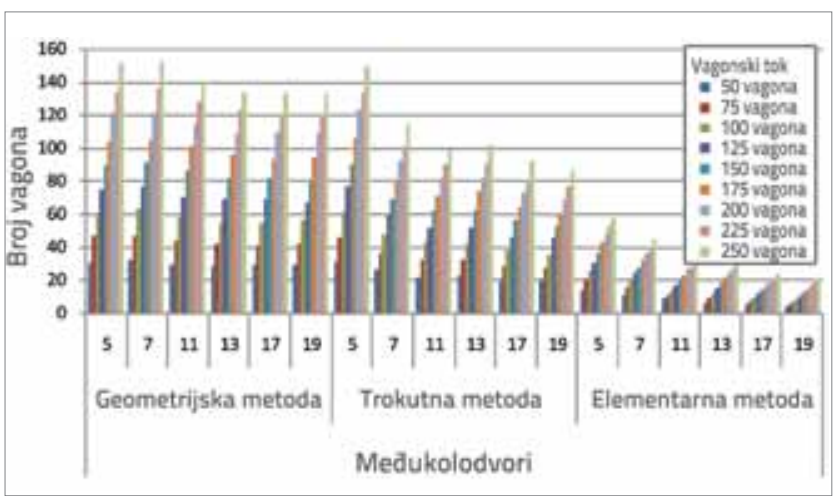

Figure 6. Individual theoretical track lengths

directly dependent on the total number of vehicles included in the forming process. Figure 6 shows that the maximum track length increases with the wagon flow rate, while the increase in the number of intermediate stations results in slight changes of such lengths. The comparison of methods shows that the elementary method requires much smaller individual theoretical tracks lengths. In the geometrical method, theoretical lengths of individual tracks are somewhat greater when compared to the triangular method. All lengths are expressed as the number of vehicles that can be positioned on the track.

In addition to the greatest track length, the length of other tracks included in the track group system must also be taken into account, in order to enable an adequate planning of track capacities. Mean track deviation values with respect to the maximum-length track are shown in Figure 7. Triangular and geometrical methods are characterized by considerable non-uniformity of tracks, especially in cases with 5, 8, 9, 18, 19, and 20 intermediate stations. Track non-uniformity for these numbers of intermediate stations is directly due to classification method used in these methods.

By closer examination of results for individual theoretical track lengths (Figure 6), it can be seen that track lengths needed to form multigroup trains are excessively great when triangular and geometric simultaneous methods are used (they require accommodation for $80-150$ vehicles), which is unacceptable from the standpoint of practical use. In fact, on such long tracks, the vehicles descending from the top of the hump would not be able to reach their destination (end of track), and so it would be necessary to perform additional manoeuvring operations, which would slow down the entire process considerably. It is therefore necessary to adopt a restriction in order to establish realistic track length relationships. This restriction should be such that an average length of these tracks corresponds to the vehicle collection length for one train, and individual deviations should not exceed $\pm 250-300 \mathrm{~m}$. The effectiveness of this measure can be seen by checking results of real mean track length deviations, shown in Figure 7. 


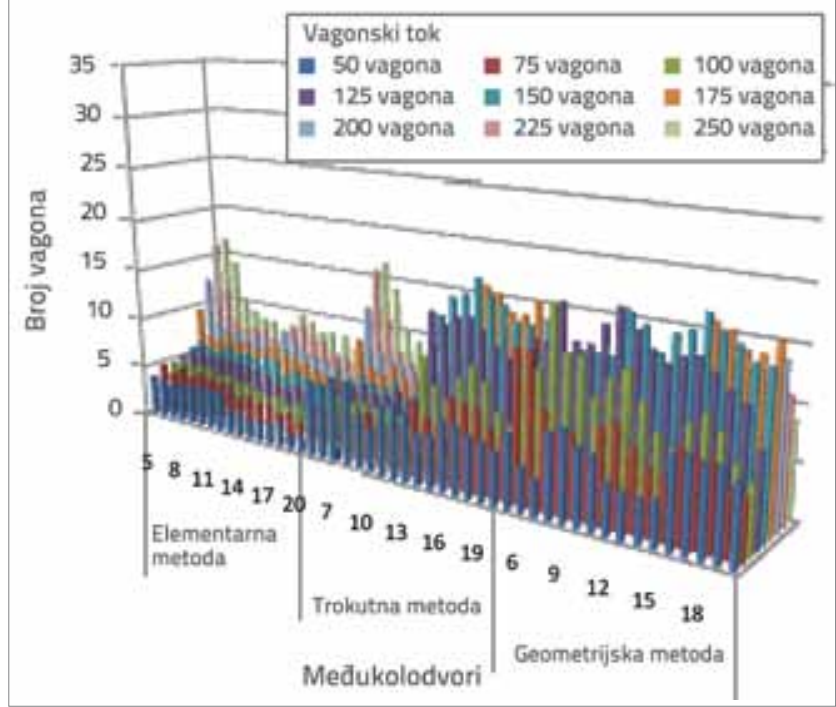

Figure 7. Theoretical mean deviation of track lengths

As already mentioned, theoretical track lengths greatly exceed the allowed values in a considerable number of cases, which results in changes in the real-life structure of track capacities. This change is reflected in an inevitable increase in the number of tracks. By limiting the track length and by increasing the number of tracks, we can balance track lengths in cases when triangular and geometric methods are used (Figure 8). On the other side, the elementary method is characterized by full uniformity of tracks at the level of theoretical assumptions, but this balance is disturbed in case of greater number of vehicles (more than 200 vehicles) at the forming stage.

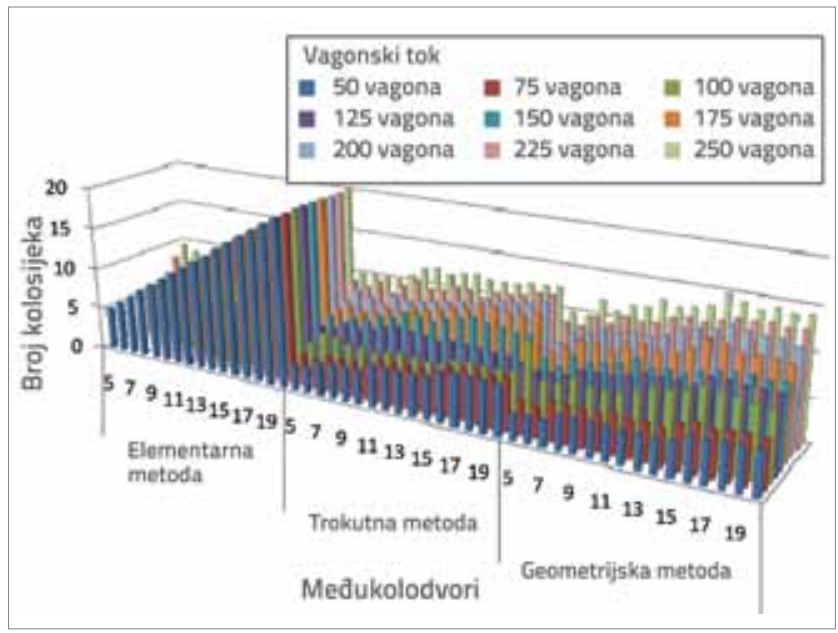

Figure 8. Real mean deviation of track lengths

The real number of tracks for the collection and sorting of vehicles by groups is shown in Figure 9. According to simulation results, the required number of tracks is relatively uniform compared to the number of intermediate stations. In real-life conditions, the total number of tracks is dominantly influenced by wagon flow. For smaller numbers of vehicles at forming stage (up to 100 vehicles), the real number of tracks remains within limits set in theoretical formulations. The number of required tracks increases with an increase in the number of vehicles at forming stage and, at that, the triangular method of forming requires the smallest number of tracks. Although in theory the geometrical method takes up the smallest number of tracks, the real number of tracks increases considerably due to great individual lengths of tracks. The number of tracks and their lengths remain within limits of theoretical formulations if the elementary method is used. Only in case of strong wagon flows (of more than 200 vehicles), and smaller number of intermediate stations (up to 6), the number of tracks would slightly increase, compared to the theoretical number. According to results obtained, we can exclude the possibility of using elementary method in case of great number of intermediate stations, because of the need to provide great number of small-length tracks.

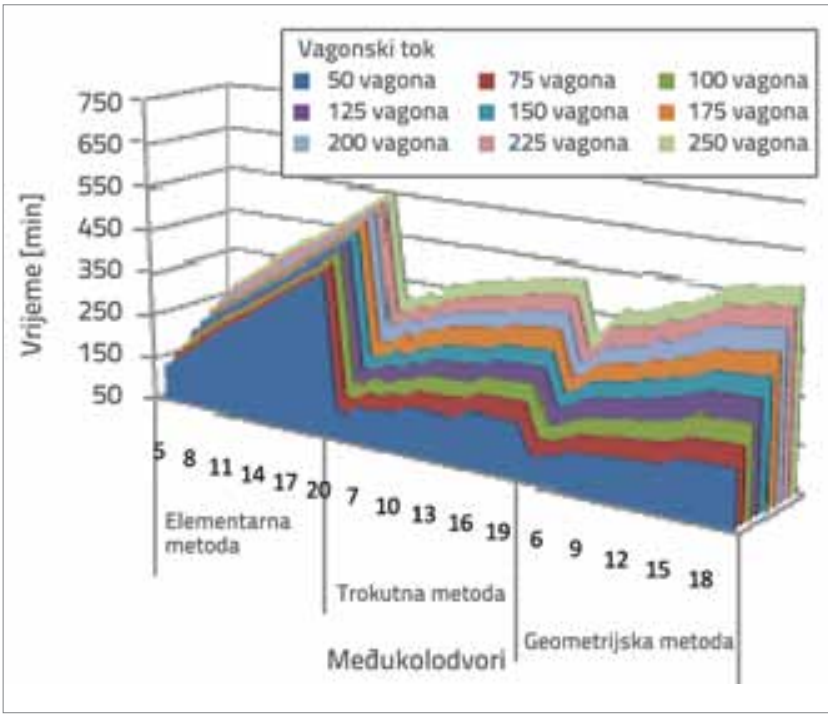

Figure 9. Real number of tracks

\subsubsection{Quality of service in stations}

The following indicators can be included in the group of indicators showing quality of service in stations: time for realization of the forming process, and the scope of vehicle manoeuvring operations or use of shunters. The time needed to form all trains, and the scope of vehicle manoeuvring operations, were analyzed for the purposes of this paper. The forming time needed is the time period starting at the first pullout of collected vehicles (or of groups of vehicles), and ending at the moment when all compositions have been distributed and formed according to the order of intermediate stations. The scope of vehicle manoeuvring operations comprises:

- total number of pullouts, corresponds to the number of tracks where vehicle collection and sorting toward intermediate stations has been performed, 
- total number of vehicles moved, comprises all vehicles moved at the sorting stage, and

- average number of movements by vehicles, is the relationship between the total number of vehicles moved and the wagon flow during formation of multigroup trains.

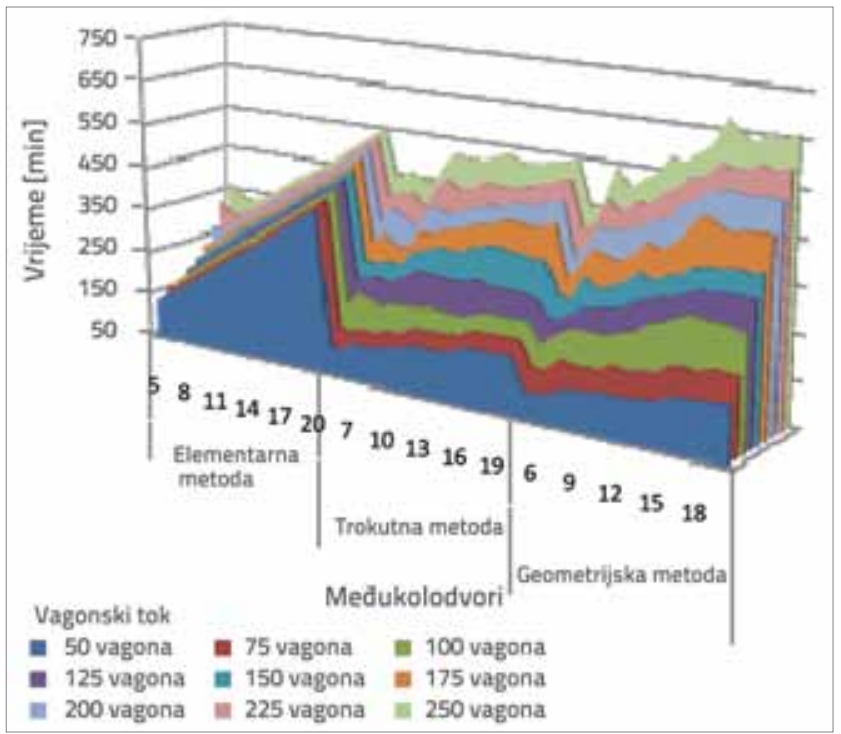

Figure 10. Theoretical forming time

Theoretical and real total train forming times are shown in Figures 10 and 11. According to relation (14), train forming times are directly dependent on the number of vehicles that are to be moved. In addition, train forming times also depend on the number of pullouts, i.e. they follow the increase in the number of intermediate stations. Because of limitations present in actual operations, the forming time remains dependent on wagon flow, but it is less dependent on the number of intermediate stations. This is due to the fact that, in real-life conditions, the number of pullouts (or tracks where collection process is accomplished) is not so dependent on the number of intermediate stations as it is in theoretical formulations, especially in cases when work is performed with a great number of vehicles.

If we compare different simultaneous forming methods, we can see that in case of geometrical and triangular methods the forming times are smaller under conditions characterized by smaller scope of work and grater number of intermediate stations. The elementary method features a smaller train forming time under conditions characterized by a greater number of vehicles. If we compare triangular method with geometrical method, we can see that the triangular method is more advantageous in that it is less dependent on the number of intermediate stations.

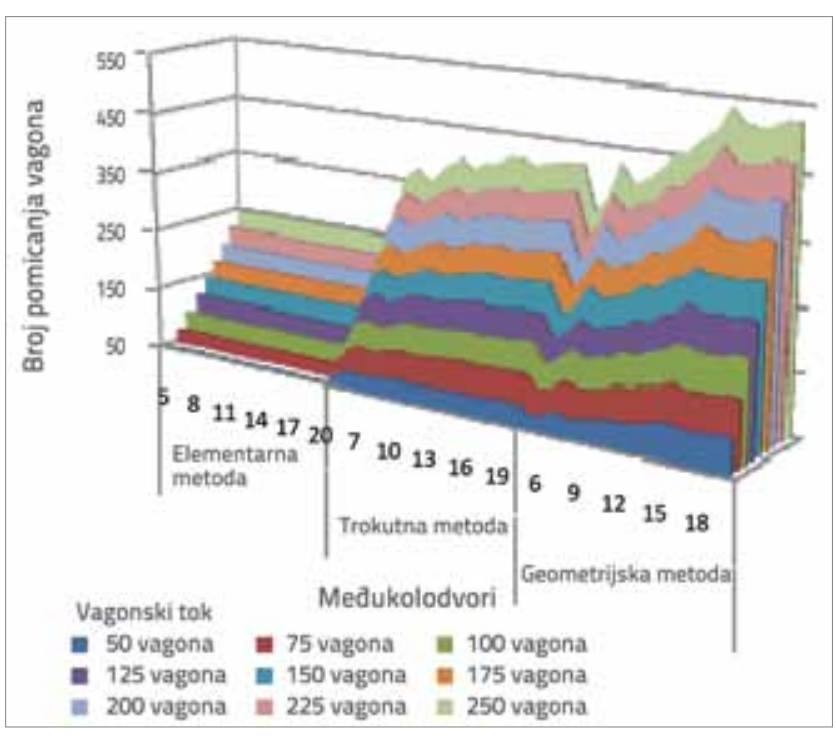

Figure 11. Real forming time

Operating conditions do not influence the total number of vehicles moved during the train forming process, and hence they are similar in both theoretical and real conditions. It can be seen from Figure 12 that the total number of vehicles moved is dependent on the method used, but also on the wagon flow and the number of intermediate stations.

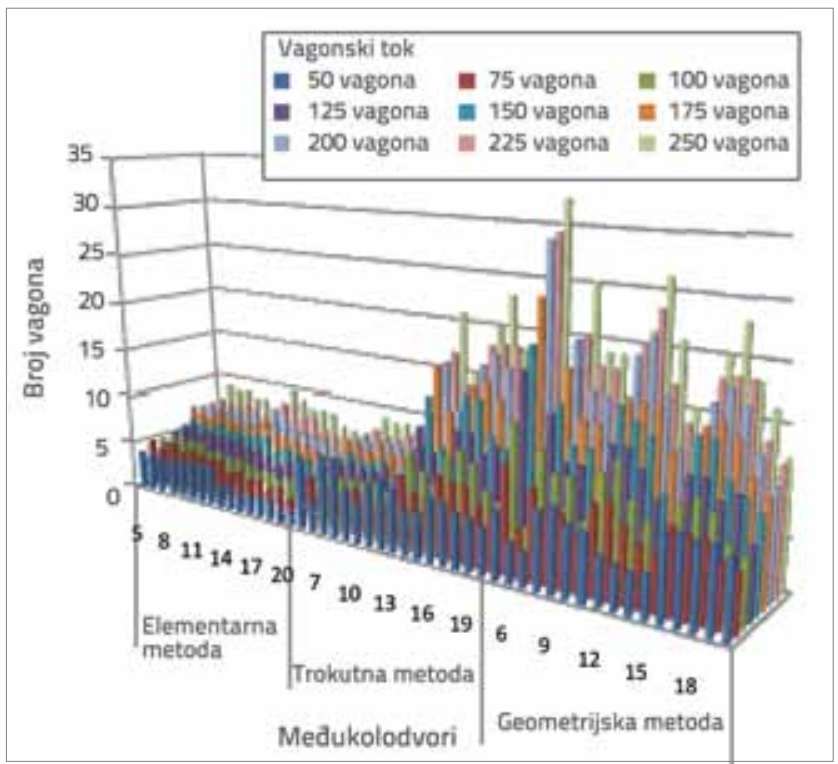

Figure 12. Total number of vehicles moved

Similar conclusions can be made by analyzing an average number of movements per vehicle (Figure 13). According to elementary method, trains are formed in such a way that all vehicles are moved only once in the course of the sorting process. In geometrical method, the number of movements per vehicle generally increases with an increase in the number of intermediate stations which exceed two movements 
(applicable to more than 15 groups). The increase is more moderate in triangular method. There the increase does not exceed two movements per vehicle in the sorting process.

The previous analysis relating to the number of tracks can fully be applied in the analysis of indicators concerning the total number of pullouts.

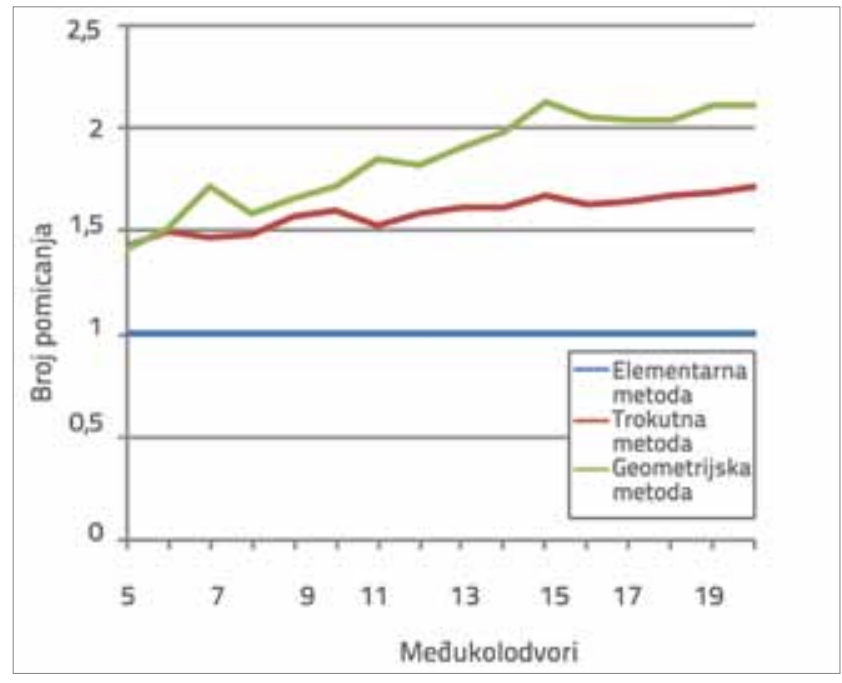

Figure 13. Average number of movements per vehicle

\section{Conclusion}

The design process and the technological planning of marshalling yards have often been conducted as separate processes, without taking into account their correlations and dependencies. For that reason, deficiencies of design solutions were usually noticed only after marshalling yards have been realized and put to use. These deficiencies are mostly seen in the capacities that are not adjusted to actual operating conditions. The effects of the use of simultaneous methods for multigroup train forming, with the focus on track capacities and quality of service, are analyzed in this paper. In addition to the analysis of theoretical bases of simultaneous methods, the technical-technological conditions for their use are also considered. It is emphasized that limitations regarding the use and design of marshalling yards greatly influence and change final effects of methods used, compared to to theoretical formulations. The comparison of methods was made based on simulation models which realistically depict the technological work process and technical conditions during simultaneous formation of trains. Results obtained in this study can not be considered sufficient for giving a precise answer about which of the methods is the most complete. The vehicle classification process is greatly influenced by the number of vehicle groups in forming process, and the wagon flow rate. The elementary simultaneous method features the best total effects with regard to formation of trains composed of smaller number of groups with a great quantity of vehicles. Simulation models have shown that triangular and geometrical forming requires a similar number of tracks, but the total track lengths are greater when geometrical method is applied. In these two methods, the uniformity of track lengths varies and is greatly dependant on the number of groups formed, while for the same number of vehicle groups the uniformity of tracks deviates with the change in the wagon flow rate. The analysis of results shows that these methods differ considerably with regard to quality of service rendered, especially under conditions characterized by a great number of vehicles at the forming stage.

As the number of simultaneous forming methods is practically unlimited, further research should be directed toward formulation of mathematical models for finding optimum plans dependant on the number of groups formed and the wagon flow. These mathematical models should be able to take into account, in addition to basic limitations regarding the group sorting order, the technical-technological conditions which are considered in this paper in the scope of simulation models.

\section{Acknowledgements}

This paper was prepared under the auspices of the Ministry of Education and Science of the Republic of Serbia in the scope of the technological project No. 36012: "Study of technicaltechnological, personnel and organizational capabilities of Serbian Railways from the standpoint of present and future EU requirements".

\section{REFERENCES}

[1] Bourgeois, M.; Valette, M.: Formation des trains de detail par la methode de la formation simultanée, Revue génèrale des Chemins de fer, 3-4(1940), 131

[2] Crane, R.; Brown, F.; Blanchard, R.: An Analysis of a Railroad Classification Yard, Journal of the Operations Research Society of America, 3(1955)3, 262 - 271.

[3] Čičak, M.; Vesković, S.: Organizacija železničkog saobraćaja II, Saobraćajni fakultet, Beograd 2005.
[4] Daganzo, C.; Dowling, R.G.; Hall, R.W.: Railroad Classification Yard Throughput: The case of multistage triangular sorting, Transportation Research Part A, 17A(1983)2, 95-106.

[5] Daganzo, C.: Static blocking at railyards: Sorting implications and track requirements, Transportation Science, 20(1986)3, 189-199.

[6] Dahlhaus, E.; Horak, P.; Mille, M.; Ryan, J.: The train marshalling problem, Discrete Applied Mathematics, 103(2000)1-3, 41-54. 
[7] Eggermont, C.; Hurkens, C.; Modelski, M.; Woeginger, G.: The hardness of train rearrangements, Operations Research Letters 37(2009)2, 80-82.

[8] Grupa autora: Studije i projekti rađeni na katedri za eksploataciju železnica, Institut Saobraćajnog fakulteta, Beograd 1975-1995.

[9] Ivić, M.; Marković, M.; Marković, A.: Effects of the application of conventional methods in the process of forming the pick-up trains, Yugoslav Journal of Operations Reseach, 17(2007)2, 245-256.

[10] Ivić, M.; Marković, A.; Milinković, S.; Belošević, l.; Marković, M.; Vesković, S.; Pavlović, N.; Kosijer, M.: Simulation model for estimating effects of forming pick-up trains by simultaneous method, Proceedings of 7th EUROSIM Congress on Modelling and Simulation, Prague 2010.

[11] Ivić, M.: Optimiacija strukture i kapaciteta kolosečnih parkova tehničkih teretnih stanica - doktorska disertacija, Saobraćajni fakultet, Beograd 1992.
[12] Marković, M.; Ivić, M.: Bezbednost, proračun i ispitivanje grbine, Saobraćajni fakultet, Beograd 2005.

[13] Márton, P.: Experimental evaluation of selected methods for multigroup train formation, Communications, 2(2005), 5-8.

[14] Petersen, E.R.: Railyard Modeling: Part I. Prediction of PutThrough Time, Transportation Science, 11(1977)1, 37-49.

[15] Petersen, E.R.: Railyard Modeling: Part II. The Effect of Yard Facilities on Congestion, Transportation Science, 11(1977)1, 51-59.

[16] Pentiga, K.J.: Teaching simultaneous marshalling, The Railway Gazette, 1959. 